\title{
Spatial quantile regression with application to high and low child birth weight in Malawi
}

Alfred Ngwira

\begin{abstract}
Background: Child low and high birth weight are important public health problems. Many studies have looked at factors of low and high birth weight using mean regression. This study aimed at using quantile regression to find out determinants of low and high birth weight.

Methods: Spatial quantile regression models at 0.05 and 0.95 percentiles of birth weight were fitted to 13,087 children birth weight in kilograms using Malawi demographic health survey data of 2010 study. Full Bayesian method by integrated nested Laplace approximations (INLA) was used to estimate the model. Second order random walk priors were assigned for mother age and antenatal visits for pregnancy while Gaussian markov random field prior was used for district of the child.
\end{abstract}

Results: Residual spatial patterns reveal areas in the southern region promoting high birth weight while areas in the central and northern region promote low birth weight. Most fixed effects findings are consistent with the literature. Richest family, normal mother body mass index (BMI), mother over weight (BMI $>25 \mathrm{~kg} / \mathrm{m}^{2}$ ), birth order $2-3$, mother secondary education and height $(\geq 150 \mathrm{~cm}$ ) negate low birth weight while weight $45-70 \mathrm{~kg}$ promote low birth weight. Birth order category $6+$, mother height $(\geq 150 \mathrm{~cm})$ and poor wealth quintile, promote high birth weight, while richer and richest wealth quintiles and education categories: primary, secondary, and higher, and mother overweight $\left(\mathrm{BMI}>25 \mathrm{~kg} / \mathrm{m}^{2}\right)$ reduce high birth weight. Antenatal visits for pregnancy reduce both low and high birth weight.

Conclusion: Strategies to reduce low and high birth weight should simultaneously address mother education, weight gain during pregnancy and poverty while targeting areas increasing low and high birth weight.

Keywords: Spatial, Quantile, Bayesian, INLA

\section{Background}

High birth weight (HBW) defined as new born weight greater than $4.5 \mathrm{~kg}$ is an emerging public health issue in developing countries [1]. It is generally accepted that HBW occurs in the range of $3-15 \%$ of all pregnancies [2]. As an emerging issue, HBW is under reported in sub-Saharan Africa. In Malawi there is no report to my knowledge regarding the prevalence of HBW. HBW according to research [3-10] carries significant risk to both the mother and the child. A high risk of shoulder dystocia has been found to be related with high birth weight

Correspondence: alfngwira@yahoo.com

Department of Basic Sciences, Lilongwe University of Agriculture and Natural Resources, Lilongwe, Malawi

(c) The Author(s). 2019 Open Access This article is distributed under the terms of the Creative Commons Attribution 4.0 International License (http://creativecommons.org/licenses/by/4.0/), which permits unrestricted use, distribution, and reproduction in any medium, provided you give appropriate credit to the original author(s) and the source, provide a link to the Creative Commons license, and indicate if changes were made. The Creative Commons Public Domain Dedication waiver (http://creativecommons.org/publicdomain/zero/1.0/) applies to the data made available in this article, unless otherwise stated. 
A number of factors influence high birth weight. HBW is associated with gestational diabetes. Birth order, a previous HBW infant, male fetus, maternal and paternal birth weight, ethnicity, gestational hypertension, preeclampsia, and increased interval between pregnancies are also known to be associated with HBW [13]. Nevertheless, studies indicate that high mother body mass index (BMI) and weight gain during pregnancy are the most important determinants of high birth weight $[14,15]$.

On the other hand, LBW is primarily caused by uterine growth retardation or preterm delivery or both. Smoking, low maternal education, young and advanced maternal age, single marital status, less weight gain during pregnancy, hypertension, genitourinary tract infection in pregnancy, first births and fewer prenatal consultations are other factors of LBW [16-19]. Furthermore, low family income, history of miscarriage is also associated with LBW [20]. In addition, being exposed to air pollutants is also known to be related with low birth weight [21]. Much research has been conducted on understanding factors for low birth weight and little attention has been paid to derterminants of high birth weight.

In addition, most studies that have looked at factors of LBW and HBW have used mean regression instead of quantile regression [22, 23]. In quantile regression we model the relationship between the covariates and the conditional quantiles of the dependent variable. The methodology supplements mean regression and provides a clearer picture of the underlying relationships of interest that can be especially useful when relationships in the extreme distribution of the response are of interest as it is the case in this study for low or high birth weight relationship with covariates.

The purpose of this research article was to investigate factors of low and high birth weight using the quantile regression so as to have an understanding of effects of covariates on the extreme distribution of the response. The modeling frame work also modeled metrical covariates non parametrically so as to capture their subtle influences. In addition, there was incorporation of spatial random effects so as to take into account the effect of unobserved area level covariates. Incorporation of spatial effects avoided the underestimation of model parameters' standard errors which if not incorporated could result in erroneous rejection of null hypothesis about significance of the covariates.

The article content is presented as follows: first, methods in terms of study population, area, data and statistical analysis are presented. Results, discussion and conclusion follow there after.

\section{Methods}

\section{Data and materials}

The study looked at children in Malawi less than 5 years and used secondary data (2010 Malawi demographic and health survey (MDHS) data). The data was accessed from the demographic health survey (DHS) website after being given permission. According to [12], the Malawi Health Research Committee, Institutional Review Board of ICF Macro and the Centre for Disease and Control (CDC) in Atlanta, USA gave the ethical approval for the MDHS study. For details on how study was designed refer to [12]. The map file for the spatial effects was provided by the Malawi National Statistical Office (NSO) licensed under Open Government Licence v.3.0 Additional file 1.

Stata version 12 (StataCorp, Texas) was used to extract and generate new variables in the data. Variables found in previous studies on child birth weight were used in this study. Child birth weight in kilograms was the dependent variable in the extracted data set and the independent variables were mother smoking status, mother age, mother education, mother height, mother weight, mother BMI, number of antenatal visits for pregnancy, birth order, wealth index and district of the child. Birth order, mother smoking status, mother education, wealth index, mother height, mother weight, mother BMI and district of the child were categorical variables. The inclusion of mother BMI, weight and height instead of either BMI or the two, weight and height was based on previous research [24] who included all the three variables. In addition, BMI separately was being used as proxy measure of mother nutrition status where low BMI means under nutrition (underweight) and high BMI means overweight, and height in particular was being used as a proxy measure of hereditary factor in influencing LBW and HBW where normally tall mothers tend to give birth to high birth weight babies and vice versa. Mother weight was being used a proxy of mother weight gain during pregnancy as there was no weight gain variable in the DHS data. The total number of live child births was 19,697. Out of this number, 13087 child births had their birth weight reported either by mother recall or from record. The missing covariate values in data set were not removed.

\section{Statistical analysis}

First bivariate quantile regression was performed in $\mathrm{R}$ using quantreg package to select potential independent variables for the multiple variable regression. Independent variables that were significant at $20 \%$ significance level were taken as candidate variables for multiple variable regression. The $20 \%$ significance level was used in selecting independent variables for multiple variable regression, to allow more potential independent variables to be selected. Cross tabulation between factor independent variables and categorized birth weight (less than $2.5 \mathrm{~kg}, 2.5 \mathrm{~kg}$ to $4.5 \mathrm{~kg}$ and greater than $4.5 \mathrm{~kg}$ ) was 
performed to have percentage distribution of low and high birth weight per factor variable levels.

Multiple variable quantile regression models were then fitted in $\mathrm{R}$ using INLA package. Quantile regression models the conditional quantiles on the covariates instead of the mean. Let $y_{i}$ be the dependent variable and $X_{i}=\left(X_{i 1}, X_{i 2}, \ldots, X_{i p}\right)$ be the vector of $\mathrm{p}$ independent variables. The quintile regression of $y_{i}$ on $X_{i}$ is defined as

$$
q\left(\tau \mid X_{i}\right)=X_{i}^{\prime} \gamma_{\tau}
$$

where $p\left(y_{i}<q\left(\tau \mid X_{i}\right)\right)=\tau \epsilon[0,1]$ is the quantile level and $\gamma_{\tau}=\left(\gamma_{1}(\tau), \gamma_{2}(\tau), \ldots, \gamma_{p}(\tau)\right)$ is the vector of $\mathrm{p}$ covariates effects. The value of $\tau$ considered in this study was 0.05 and 0.95 where 0.05 corresponds to low birth weight (birth weight $=2.5 \mathrm{~kg}$ ), and 0.95 corresponds to high birth weight (birth weight $=4.5 \mathrm{~kg}$ ). If $\tau=0.5$, then we have the usual linear regression, that is, mean regression. Model (1) assumes that the predictor is linear and in the presence of non linear and spatial predictors (1) becomes:

$$
\begin{aligned}
q\left(\tau \mid X_{i}\right)= & w_{i}^{T} \gamma_{\tau}+f_{1(\tau)}\left(x_{i 1}\right)+f_{2(\tau)}\left(x_{i 2}\right)+\ldots \\
& +f_{p(\tau)}\left(x_{i p}\right)
\end{aligned}
$$

where $f_{j}$ for $j=1,2,3, \ldots, p$ represent the effect of non linear independent variables including the spatial effect. The vector of coefficients $\gamma_{\tau}$ determine the parametric relationship between the response and the categorical covariates. The two unknown parameters $\gamma_{\tau}, f_{j(\tau)}$ are normally estimated via minimization problem

$$
\left(\begin{array}{c}
\min \\
\gamma_{\tau}, f_{j(\tau)}
\end{array}\right)=\sum \rho_{\tau} n_{\tau_{i}}+\lambda_{0}|| \beta_{\tau}|| 1+\sum_{j=1}^{q} \lambda_{j} V\left(\nabla_{\tau_{i}}\right)
$$

where $\rho_{\tau}$ is the loss function for the given $\tau$ and $\lambda_{0}$ is the intial smooth paramer for function $f_{j(\tau)}$ and $\lambda_{j}$ is $j$ smooth parameter, $\left\|\beta_{\tau}\right\| 1=\sum_{k=1}^{k}\left|\beta_{\tau_{k}}\right|$ and $V\left(\left(\nabla_{\tau_{i}}\right)\right.$. denote the total variation of the derivative on the gradient of the function $f_{\tau_{i}}$.

Since model inference was fully Bayesian, all parameters were assigned priors. The smooth functions for metrical/spatial covariates $f_{\tau}($.$) were assigned functions from$ Gaussian markov random field (GMRF) family, that is, if $f_{\tau}($.$) has mean \mu$ and precision matrix $\delta Q$, it is assumed to have the density of the form

$$
[f \mid \delta] \propto \delta^{n-m / 2} \exp \left(-\frac{\delta}{2}(f-\mu)^{\prime} Q(f-\mu)\right)
$$

where $Q$ is the semi-definite matrix of constants with rank $n-m(m \geq 0)$ which also determines the kind of the particular GMRF. For the metrical covariates, we selected the second order random walk (RW2) priors [25], and the spatial effects were assigned the intrinsic conditional autoregressive (ICAR) [26]. The selection of RW2 prior for metrical covariates was to be more flexible in capturing the nonlinear relationship considering that RW2 prior corresponds to the locally quadratic fit and first order random walk prior (RW1) corresponds to locally linear fit according to [27]. The selection of GMRF in general for all non linear terms was from the fact that the use of GMRF prior was appropriate for the spatial covariate as data was based on the level of geographical region (district), that is, the exact data locations were not known so as to use the two dimensional penalized spline according to [27]. In this case if $n_{i}$ denotes the number of neighbours for site $s_{i}$ then the spatial effect prior distribution is

$$
\left.f\left(s_{i} \mid s_{j}\right) \sim N\left(\frac{1}{n_{i}} \sum_{i \neq j}^{n_{i}} f\left(s_{j}\right), \frac{1}{\delta n_{i}}\right)\right)
$$

The fixed effects were assigned diffuse priors i.e. $\left[\gamma_{\tau}\right] \propto$ constant. In this case we assumed prior ignorance for the fixed effects and had let the data speak for itself in estimation of parameters.

Inference of joint posterior distribution of model parameters was by integrated nested laplace approximations (INLA). Other methods like markov chain monte carlo (MCMC) could be used to infer about posterior distribution but INLA approach is faster for the quantile regression than MCMC according to [28]. Model inference was not design based, as this is common in Bayesian inference [29]. According to [30] the true Bayesian analyst does not use survey weights as the focus is on reliable statistical models rather than on assessing the degree to which their estimates are nationally representative or not.

\section{Results}

Since the bivariate analysis was similar to that of [22] the results here are almost the same. Young mothers aged 20 years or less and older mothers aged 35-49 years, have higher prevalence of low child birth weight than mothers aged 20-34 years, and prevalence of high birth weight seems to increase with increase in mother age $\left(\mathrm{X}^{2}=24.93, p<0.001\right)$ (Table 1$)$. Similar to [22], in terms of birth order number, the prevalence of low birth weight babies is higher for first born babies than babies born later while prevalence of high birth weight is higher for higher order number babies $\left(\mathrm{X}^{2}=28.41, p<0.001\right)$. An indirect relationship exists between low or high birth weight and mother education $\left(X^{2}=19.1, p<0.001\right)$. The same relationship is observed between low or high birth weight and wealth quintile $\left(\mathrm{X}^{2}=20.49, p<0.001\right)$. In this case, the percentage of low or high birth weight babies decreases with increase in education and household wealth. Looking at the regions (Table 2), central region has the highest prevalence of low birth weight infants and the southern region has the smallest, that is, 14 and 
Table 1 Percentage distribution of low and high birth weight for some covariates and the bivariate Pearson Chi-square test

\begin{tabular}{|c|c|c|c|}
\hline Variable & $\begin{array}{l}\text { Birth weight less } \\
\text { than } 2.5 \mathrm{~kg}\end{array}$ & $\begin{array}{l}\text { Birth weight } \\
\text { more than } \\
4.5 \mathrm{~kg}\end{array}$ & $\begin{array}{l}\text { Pearson } \\
\text { Chi-squared } \\
\text { (P-value) }\end{array}$ \\
\hline \multicolumn{4}{|l|}{ Mother age at birth } \\
\hline$<20$ & 15.4 & 4.7 & $24.93(<0.001)$ \\
\hline $20-34$ & 11.2 & 5.1 & \\
\hline $35-49$ & 14.5 & 6.6 & \\
\hline \multicolumn{4}{|l|}{ Birth order } \\
\hline 1 & 15.0 & 4.4 & $28.41(<0.001)$ \\
\hline $2-3$ & 11.0 & 4.6 & \\
\hline $4-5$ & 11.0 & 5.8 & \\
\hline $6+$ & 13.3 & 7.2 & \\
\hline \multicolumn{4}{|l|}{ Mother smoking } \\
\hline Smoke tobacco & 14.0 & 5.6 & $0.02(0.992)$ \\
\hline Does not & 12.3 & 5.3 & \\
\hline \multicolumn{4}{|l|}{ Mother education } \\
\hline No education & 13.3 & 8.0 & $19.10(<0.001)$ \\
\hline Primary & 12.8 & 5.5 & \\
\hline Secondary & 10.2 & 2.8 & \\
\hline Higher & 7.0 & 1.9 & \\
\hline \multicolumn{4}{|l|}{ Wealth index } \\
\hline Poorest & 13.5 & 6.3 & $20.49(<0.001)$ \\
\hline Poor & 13.2 & 6.7 & \\
\hline Rich & 12.6 & 5.7 & \\
\hline Richer & 11.8 & 4.6 & \\
\hline Richest & 10.6 & 3.1 & \\
\hline
\end{tabular}

$11 \%$ respectively. The central and southern regions have relatively higher prevalence of high birth weight (5.7\%) than northern region (4\%). Districts in the northern region do not vary in proportion of children with low or high birth weight $\left(\mathrm{X}^{2}=6.78, p=0.148\right)$ compared to districts in the central $\left(\mathrm{X}^{2}=19.90, p=0.011\right)$ and southern region $\left(\mathrm{X}^{2}=26.97, p=0.008\right)$.

Table 3 presents results from the fitted quantile regression models of birth weight at 5, and 95\% percentile. The 5\% percentile corresponds to low birth weight (birth weight $<=2.5 \mathrm{~kg}$ ) and $95 \%$ percentile corresponds to high birth weight (birth weight $=>4.5 \mathrm{~kg}$ ). The model fit statistics (deviance information criterion (DIC) and the marginal log-likelihood (LL)) show that the model at 5\% percentile fit the data well as it has the smaller DIC and larger log-likelihood than model at 95\%. The fixed effect variables significant to low birth weight with positive association are wealth category of richest family (coefficient: 0.1365 ; 95\% CI: 0.0807, 0.1923), smoking (coefficient: $0.2409 ; 95 \% \mathrm{CI}: 0.0708,0.4100)$, mother normal BMI (coefficient: 0.3587; 95\% CI: 0.2609, 0.4569), mother
Table 2 Prevalence of low and high birth weight by district and bivariate Pearson Chi-squared test

\begin{tabular}{|c|c|c|c|}
\hline District & $\begin{array}{l}\text { Birth weight less } \\
\text { than } 2.5 \mathrm{~kg}\end{array}$ & $\begin{array}{l}\text { Birth weight more } \\
\text { than } 4.5 \mathrm{~kg}\end{array}$ & $\begin{array}{l}\text { Pearson Chi- } \\
\text { square }\end{array}$ \\
\hline Northern Region & 11.6 & 4.0 & $6.78(0.148)$ \\
\hline Chitipa & 9.6 & 3.3 & \\
\hline Karonga & 8.9 & 10.4 & \\
\hline Nkhata-bay & 9.6 & 1.2 & \\
\hline Rumphi & 9.5 & 2.8 & \\
\hline Mzimba & 13.6 & 3.7 & \\
\hline Central Region & 13.5 & 5.7 & $19.90(0.011)$ \\
\hline Kasungu & 11.9 & 6.5 & \\
\hline Nkhota-kota & 11.3 & 5.3 & \\
\hline Ntchisi & 12.3 & 6.0 & \\
\hline Dowa & 13.1 & 4.8 & \\
\hline Salima & 11.0 & 4.5 & \\
\hline Lilongwe & 17.2 & 4.9 & \\
\hline Mchinji & 14.8 & 3.0 & \\
\hline Dedza & 13.0 & 8.6 & \\
\hline Ntcheu & 9.2 & 7.4 & \\
\hline Southern Region & 11.3 & 5.7 & $26.97(0.008)$ \\
\hline Mangochi & 9.4 & 6.8 & \\
\hline Machinga & 9.5 & 6.4 & \\
\hline Zomba & 10.1 & 6.6 & \\
\hline Chiradzulu & 12.2 & 8.2 & \\
\hline Blantyre & 12.6 & 5.9 & \\
\hline Mwanza & 9.3 & 4.0 & \\
\hline Thyolo & 16.7 & 4.5 & \\
\hline Mulanje & 11.1 & 3.7 & \\
\hline Phalombe & 9.9 & 9.5 & \\
\hline Chikhwawa & 10.5 & 4.3 & \\
\hline Nsanje & 7.5 & 5.3 & \\
\hline Balaka & 11.0 & 3.8 & \\
\hline Neno & 16.9 & 4.2 & \\
\hline
\end{tabular}

BMI $>25 \mathrm{~kg} / \mathrm{m}^{2}$ (coefficient: $\quad 0.2008 ; \quad 95 \%$ CI: 0.0976 , 0.2895 ), birth order $4-5$ (coefficient: 0.0978 ; $95 \% \mathrm{CI}$ : $0.0195,0.1859$ ), mother secondary education (coefficient: 0.1388 ; 95\% CI: $0.0603,0.2259$ ), mother height $\geq 150 \mathrm{~cm}$ (coefficient: 0.2662; 95\% CI: 0.1627, 0.3517), and variable with negative association is weight $45-70 \mathrm{~kg}$ (coefficient: -0.1559 ; $95 \%$ CI:-0.2627, - 0.0048). For the $95 \%$ percentile model, birth order category $6+$ (coefficient: 0.1731 ; $95 \%$ CI: $0.0489,0.3082)$ and mother height $\geq 150 \mathrm{~cm}$ (coefficient: 0.3184 ; 95\% CI: $0.1069,0.4814$ ) have a positive association with birth weight, that is, they promote high birth weight, while poor wealth index (coefficient: 0.0746; 95\% CI: 0.0106, 0.1378), richer wealth index (coefficient: -0.0732 ; 95\% CI: $-0.1378,-0.0112)$, richest 
Table 3 Summary of quantile regression models

\begin{tabular}{|c|c|c|}
\hline Variable & $\tau=0.05(L B W)$ & $\mathrm{T}=0.95(\mathrm{HBW})$ \\
\hline Normal BMI $(18.50-25$ kg/m²) & $0.3587(0.2609,0.4569)$ & $-0.0069(-0.1569,0.1274)$ \\
\hline Mother $\mathrm{BMI}>25 \mathrm{~kg} / \mathrm{m}^{2}$ & $0.2008(0.0976,0.2895)$ & $-0.2378(-0.3781,-0.0697)$ \\
\hline Smoke (yes) & $0.2409(0.0708,0.4100)$ & $0.3155(-0.0044,0.6142)$ \\
\hline Birth order 2-3 & $-0.0165(-0.0688,0.0363)$ & $0.0155(-0.0513,0.0858)$ \\
\hline Birth order 4-5 & $0.0978(0.0195,0.1859)$ & $0.0793(-0.0152,0.1772)$ \\
\hline Birth order $6+$ & $-0.0120(-0.1163,0.1034)$ & $0.1731(0.0489,0.3082)$ \\
\hline Primary education & $0.0213(-0.0346,0.0838)$ & $-0.2115(-0.2912,-0.1404)$ \\
\hline Secondary education & $0.1388(0.0603,0.2259)$ & $-0.5371(-0.6266,-0.4518)$ \\
\hline Higher education & $0.0511(-0.3984,0.3367)$ & $-0.8267(-1.0646,-0.4284)$ \\
\hline Poor & $-0.0141(-0.0706,0.0530)$ & $0.0746(0.0106,0.1378)$ \\
\hline Rich & $0.0364(-0.0208,0.0942)$ & $0.0479(-0.0167,0.1105)$ \\
\hline Richer & $-0.0128(-0.0694,0.0500)$ & $-0.0732(-0.1378,-0.0112)$ \\
\hline Richest & $0.1365(0.0807,0.1923)$ & $-0.1102(-0.1875,-0.0335)$ \\
\hline Mother height $\geq 150 \mathrm{~cm}$ & $0.2662(0.1627,0.3517)$ & $0.3184(0.1069,0.4814)$ \\
\hline Mother weight (45-70 kg) & $-0.1559(-0.2627,0.0048)$ & $-0.1777(-0.4115,0.0417)$ \\
\hline Mother weight > $70 \mathrm{~kg}$ & $0.0680(-0.0438,0.2173)$ & $-0.1757(-0.43890 .0197)$ \\
\hline \multicolumn{3}{|l|}{ Variance parameters } \\
\hline Mother age & 0.1412 & 0.2004 \\
\hline Antenatal visits & 0.0165 & 0.0001 \\
\hline Structured spatial effects & 0.0121 & 0.0014 \\
\hline \multicolumn{3}{|l|}{ Model fit statistics } \\
\hline $\mathrm{LL}$ & $-19,390.79$ & $-22,565.51$ \\
\hline DIC & $38,357.7$ & $44,731.5$ \\
\hline
\end{tabular}

wealth index (coefficient: -0.1102, 95\% CI: - 0.1875, 0.0335 ) and education categories: primary (coefficient: -0.2115 ; 95\% CI:-0.2912, - 0.1404), secondary (coefficient: -0.5371 ; 95\% CI:-0.6266, - 0.4518), higher (coefficient: $-0.8267 ;$ 95\% CI: - 1.0646, - 0.4284), mother BMI $>25 \mathrm{~kg} / \mathrm{m}^{2}$ (coefficient: -0.2378; 95\% CI: - 0.3781, 0.0697)) are negatively related with birth weight on higher values of birth weight.

Figure 1 presents non linear effect of mother age to low birth weight. There seems almost constant effect of mother age in small fluctuating amplitude manner on child low birth weight, that is, as mother age increases, its effect on child birth weight remains more or less the same. The same trend is observed for the effect of mother age on high birth weight (Fig. 2). For the non linear effect of mother antenatal visits for pregnancy to low birth weight (Fig. 3), as the number of antenatal visits increases, birth weight also increases but then, as it further increases, birth weight start to drop. The same effect trend is observed for the effect of antenatal visits on high birth weight (Fig. 4) with a weaker positive effect for the fewer antenatal visits.

Figure 5 presents structured spatial effects to low birth weight. Spatial effects are the surrogates of correlated unobserved influences to the response (e.g birth weight). There seems residual spatial variation to childhood low birth weight with the most areas in the south inhibiting low birth weight where as areas in the central and northern region promote low birth weight. The same pattern is observed for the structured spatial effect on higher values of birth weight (Fig. 6), that is, areas in the south promote high birth weight while areas in centre and north inhibit high birth weight. Both spatial effects were not significant though as the credible intervals maps show no color variation among all the districts (Fig. 7 and Fig. 8), that is they all have the same grey color which corresponds to zero, meaning insignificant. For orientation on interpreting posterior probability maps one can read [31, 32].

\section{Discussion}

This study employs the use of spatial quantile regression to explore the relationship of birth weight with its covariates at different quantiles of birth weight while taking into account residual spatial effects. Investigating covariate effect at different response quartiles is important as relationship may be different at different levels of the response. Not only relationships may be different at 


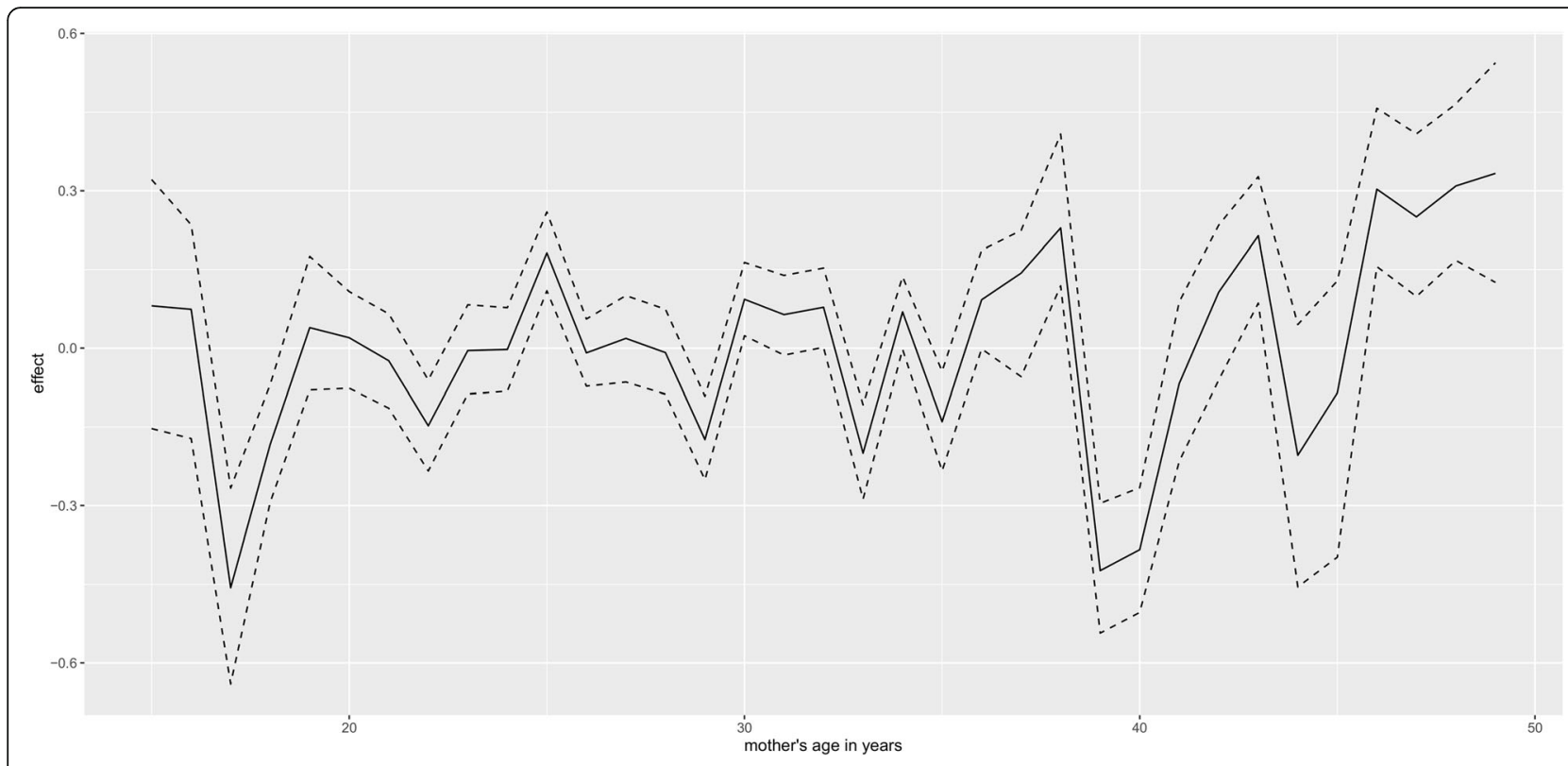

Fig. 1 Non linear effect of mother age to low birth weight

different quantiles of the response but also the significance of these relationships. For example in this study, birth order category $4-5$ is significant at $5 \%$ percentile and is insignificant at $95 \%$ percentile. Quantile regression also allows one to model percentiles of interests of the data, for example, extreme values of the data, as it is the case in this study where the interest was to investigate factors affecting high and low birth weight.

Fixed effects factors found as significant predictors of lower values of birth weight is wealth category of richest family, smoking status, mother normal BMI, mother over weight (BMI $>25 \mathrm{~kg} / \mathrm{m}^{2}$ ), birth order category 2-3, mother secondary education, and height $(\geq 150 \mathrm{~cm})$ with positive association and variables with negative association (promoting low birth weight) is weight $45-70 \mathrm{~kg}$. For the $95 \%$ percentile model, birth order category $6+$ and mother height $(\geq 150 \mathrm{~cm})$ and poor wealth quintile have a positive association with birth weight, that is, they promote high birth weight, while richer wealth index, richest wealth quintile and education categories:

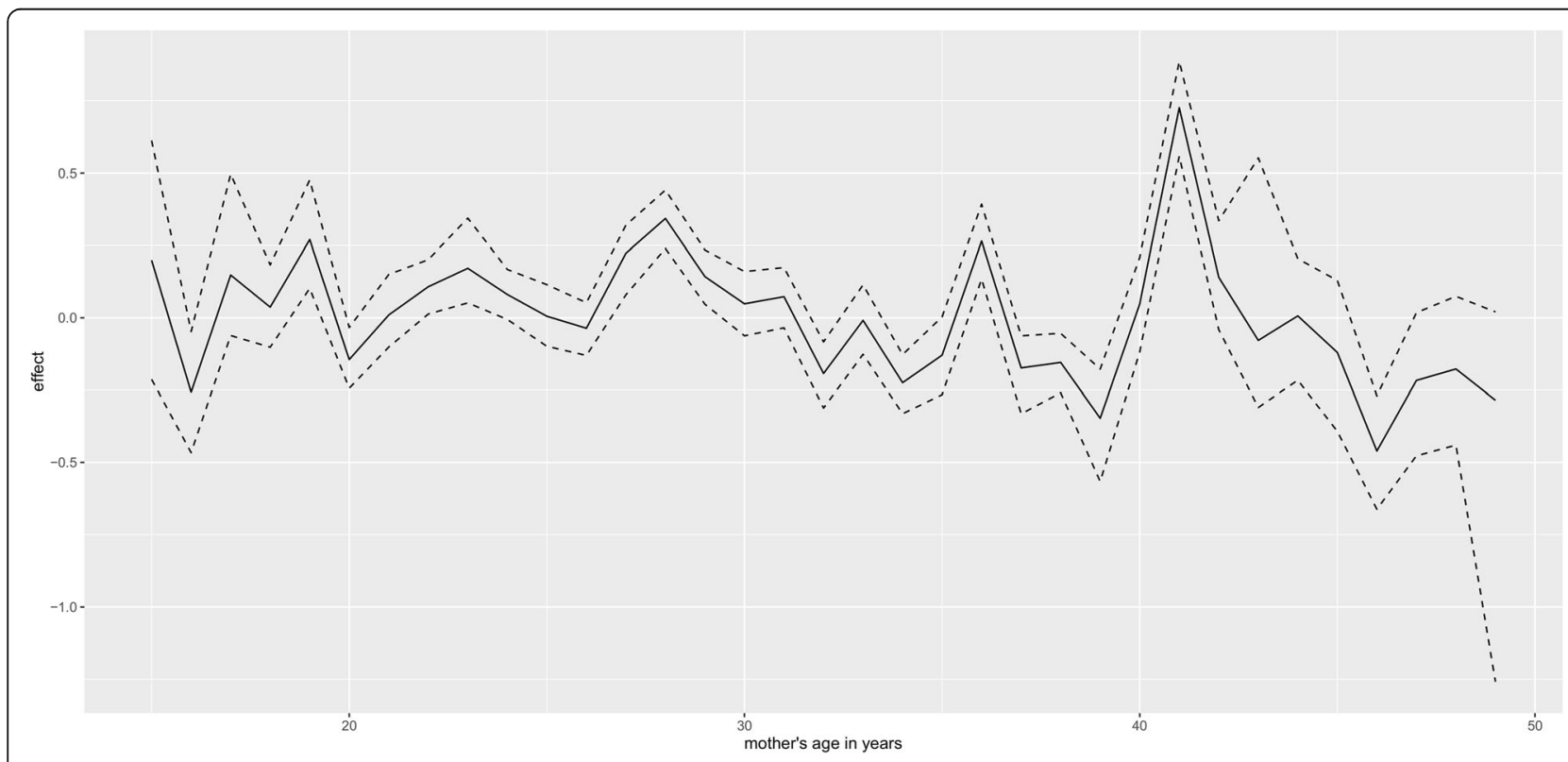

Fig. 2 Non linear effect of mother age to high birth weight 


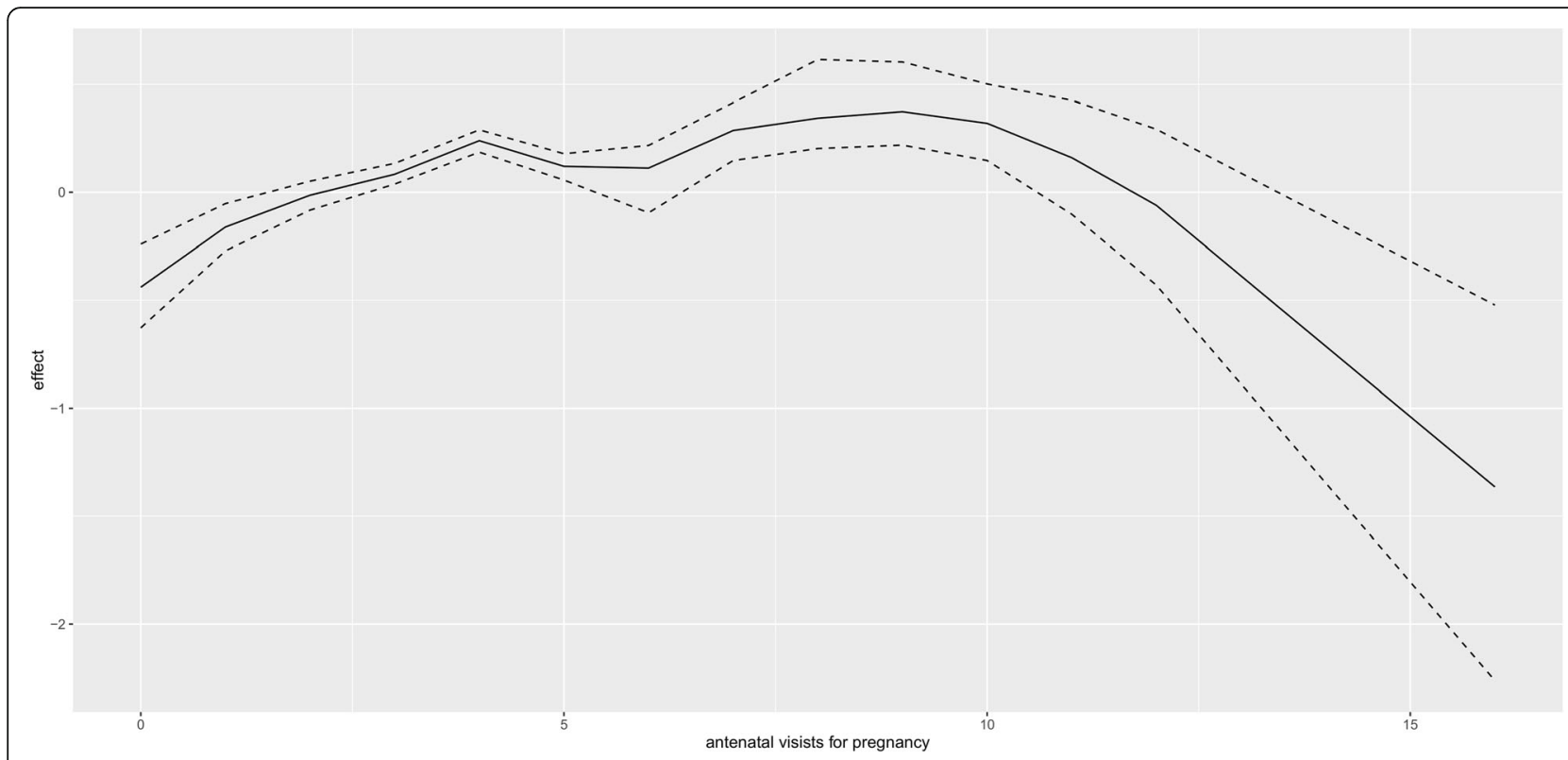

Fig. 3 Non linear effect of antenatal visits to low birth weight

primary, secondary, and higher, mother overweight $\left(\mathrm{BMI}>25 \mathrm{~kg} / \mathrm{m}^{2}\right)$ have a negative association with birth weight. Poor wealth quantile promoting high birth weight may seem unexpected but sometimes it has been found like this, for example [33] found a similar result where low socio economic status was associated with high birth weight in British Colombia region. The possible cause would be that, normally poverty is associated with improper diet, for example eating fats only which would in turn increase birth weight. Birth order positive association with birth weight is in agreement with [34] where birth order was found as an important factor influencing birth weight and that first order babies are more likely to be small babies than higher order births. Family wealth index of richest category is positively correlated with low birth weight and negatively correlated with high birth weight. According to [1], "family wealth index is a proxy measure of socio economic status of the child and high socio-economic status people are better able to avoid negative health outcomes and therefore

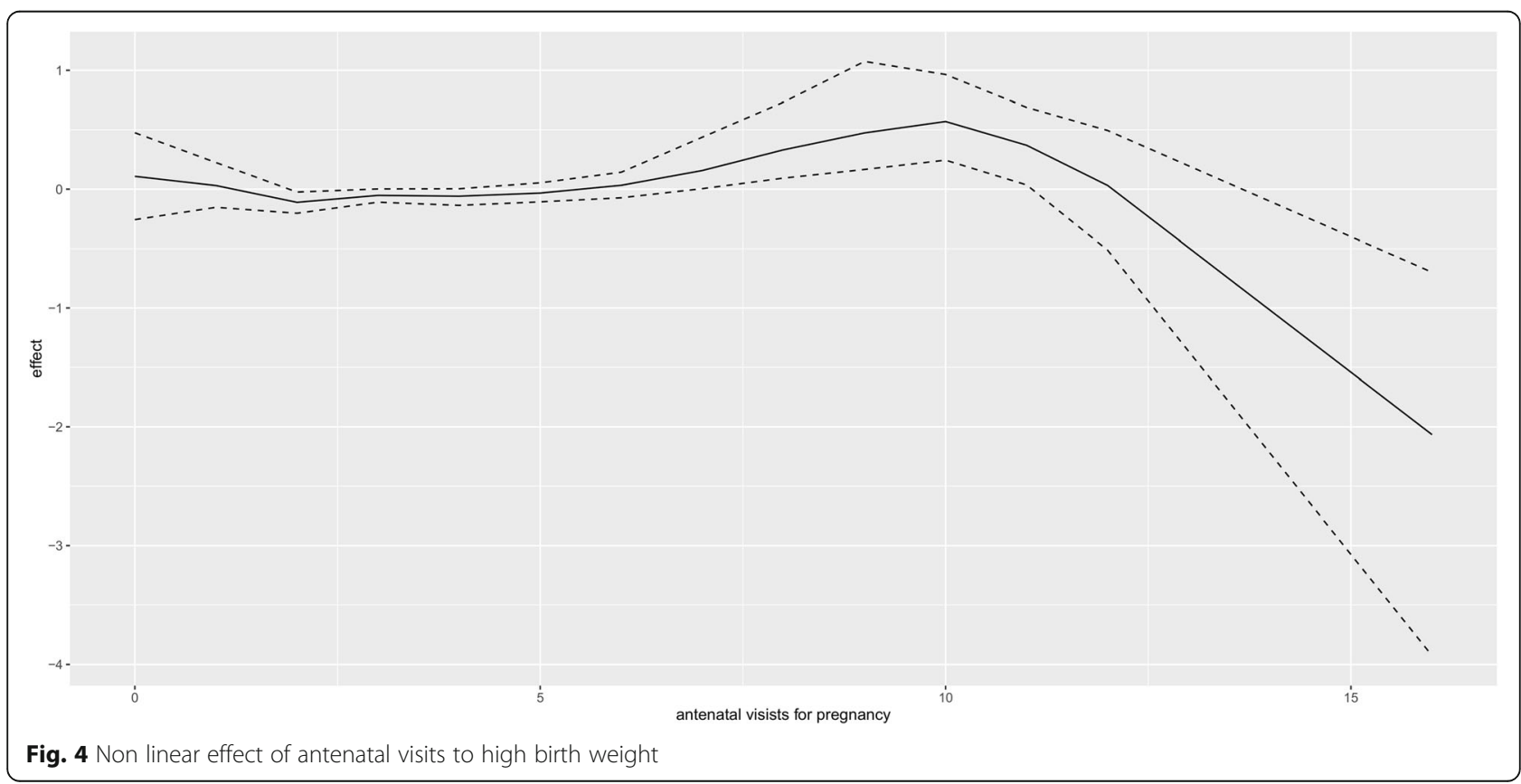




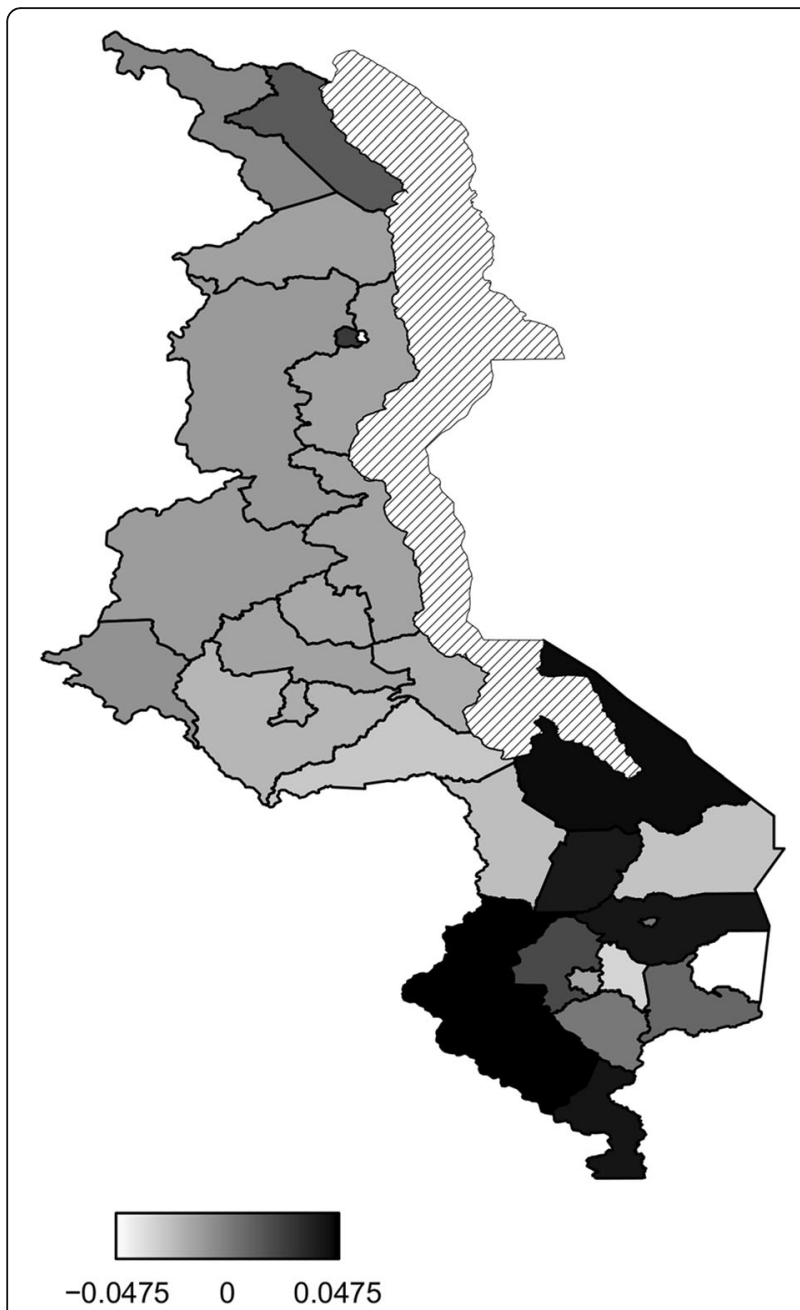

Fig. 5 Structured spatial effect to low birth weight (Map file source: National Statistical Office (www.nsomalawi.mw) licensed under the Open Government License v.3.0)

will have a lower incidence of high birth weight", at the same time will not have low birth weight. Mother body mass index behaves in the similar manner as family wealth by being negatively correlated with high birth weight and positively correlated with low birth weight. Smoking positive correlation with birth weight across all the two modeled quantiles contradicts the common literature finding $[3,35]$, though its effect is not significant at $95 \%$ percentile. The unexpected effect of smoking on birth weight is likely due to lack of taking into account unmeasured positive confounders of smoking on birth weight. Future research therefore can carefully include all possible confounders of smoking to accurately investigate its effect on birth weight. Education relationship with low and high birth weight values is positive and negative respectively, implying negating both extreme values. This is so as mothers who are educated are likely to eat proper diet to

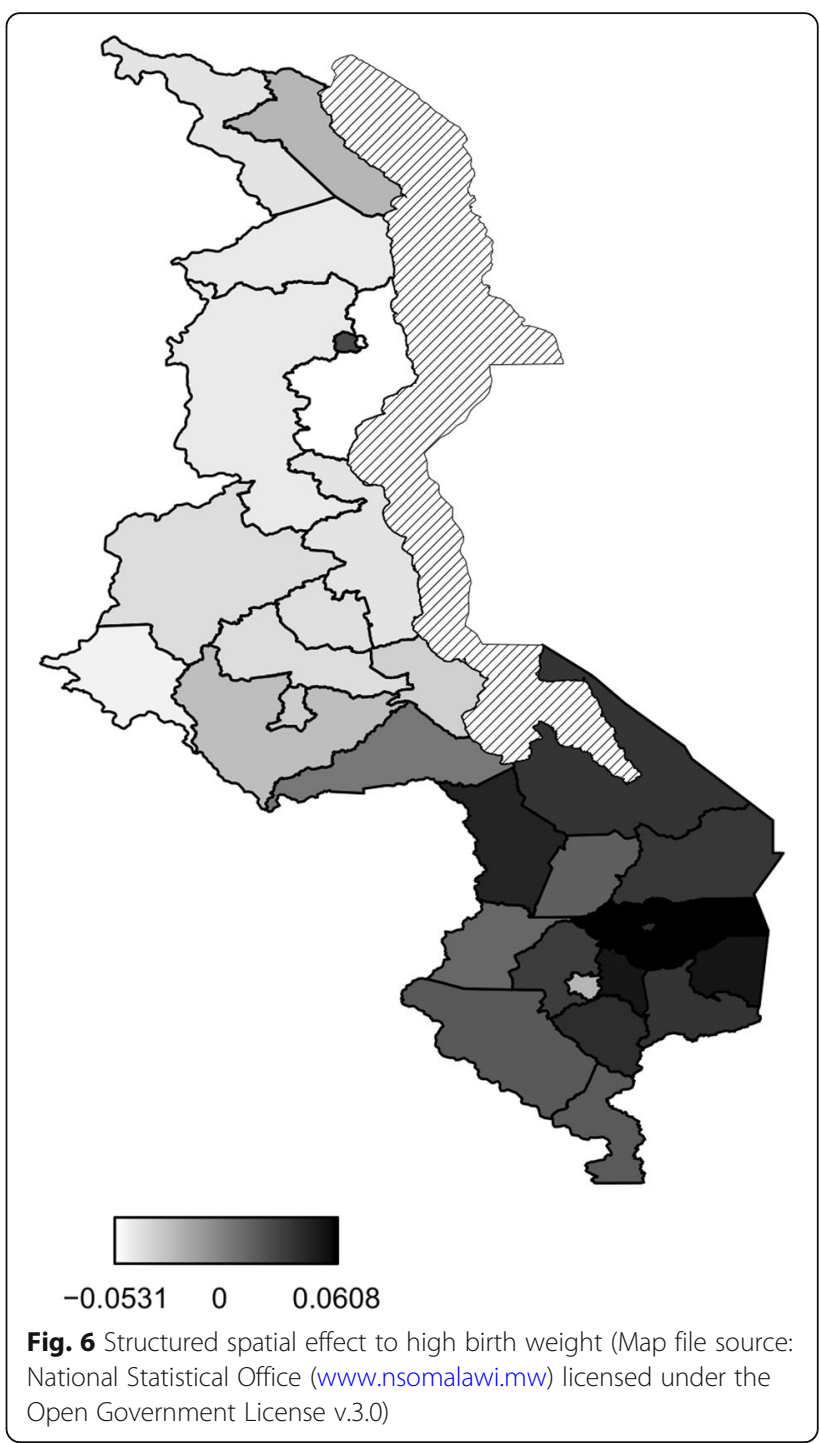

reduce low birth weight but also they may also know the dangers of over nutrition unlike uneducated mothers there by avoiding high birth weight children. Mother height has positive relationship with birth weight on lower and higher values of birth weight. This relationship is making sense since taller children will inherit their taller mothers and hence larger birth weight as height is directly proportional to weight. Mother higher weight during pregnancy (weight $>70 \mathrm{~kg}$ ) promote high birth weight for lower birth weight values and at same time reduce high birth weight for high birth weight values though not significant at these extreme values, that is, it negate both extreme birth weight outcomes (low and high).

The nonlinear effect of mother age on birth weight is almost the same on lower and high values of birth. With prenatal visits, there is a positive association with low values of birth weight for the fewer number of antenatal visits and a negative correlation with increased number 


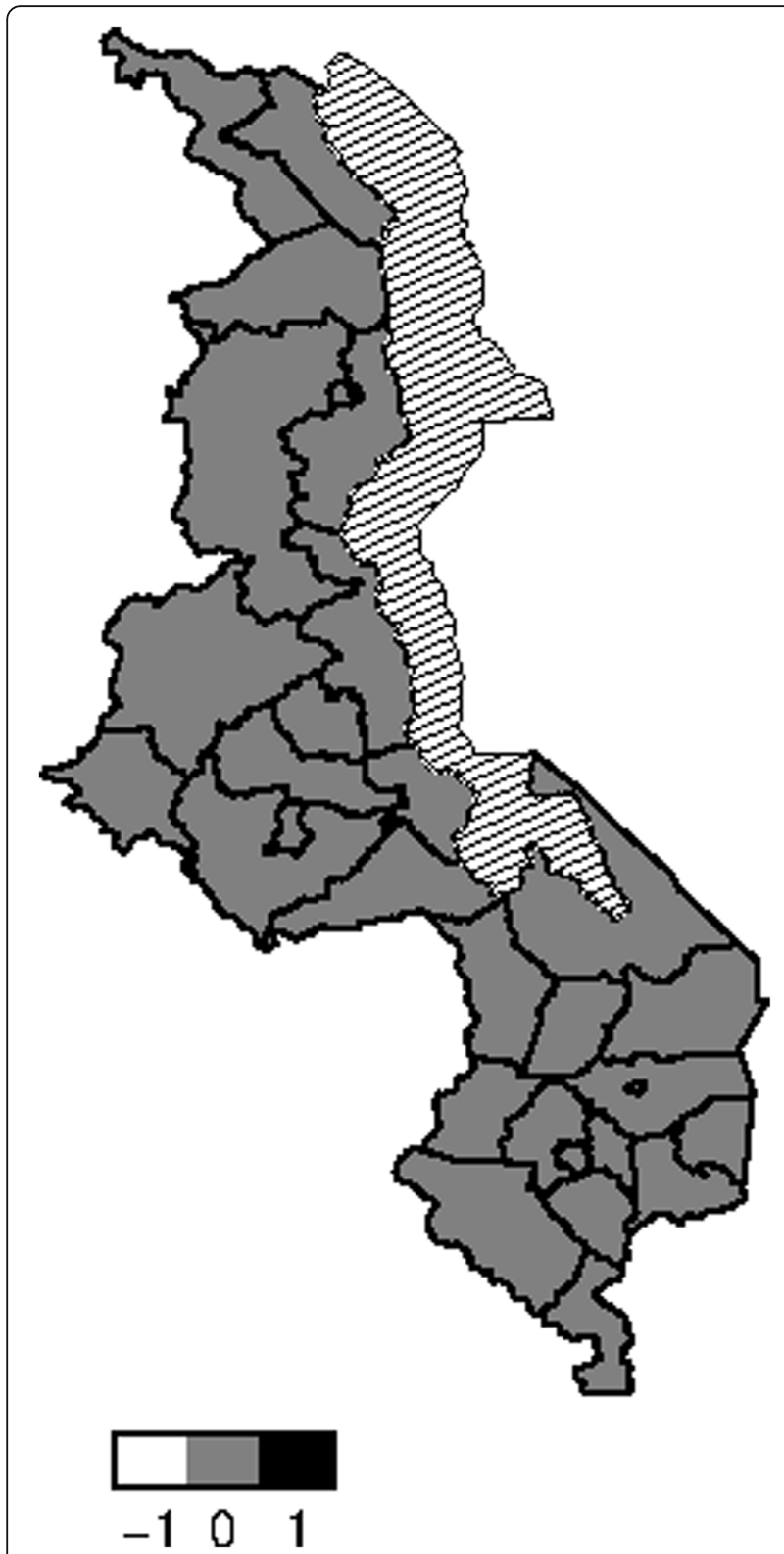

Fig. 7 95\% credible intervals map of spatial effect to LBW (white means negative effect, grey means insignificant, black means positive effect, and white with lines means lake) (Map file source: National Statistical Office (www.nsomalawi.mw) licensed under the Open Government License v.3.0)

of antenatal visits. For high birth weight, the effect of antenatal visits start in flattening out mode and then ends with strong reducing effect. This finding is consistent with [36] where antenatal visits had a stronger increasing effect for lower values (negating low birth weight) but then flattens out for larger values.

The residual spatial patterns observed in low and high child birth weight are likely due to unmeasured factors not represented in the models, and it is a matter of suggestion to find them. According to [37], the area natural

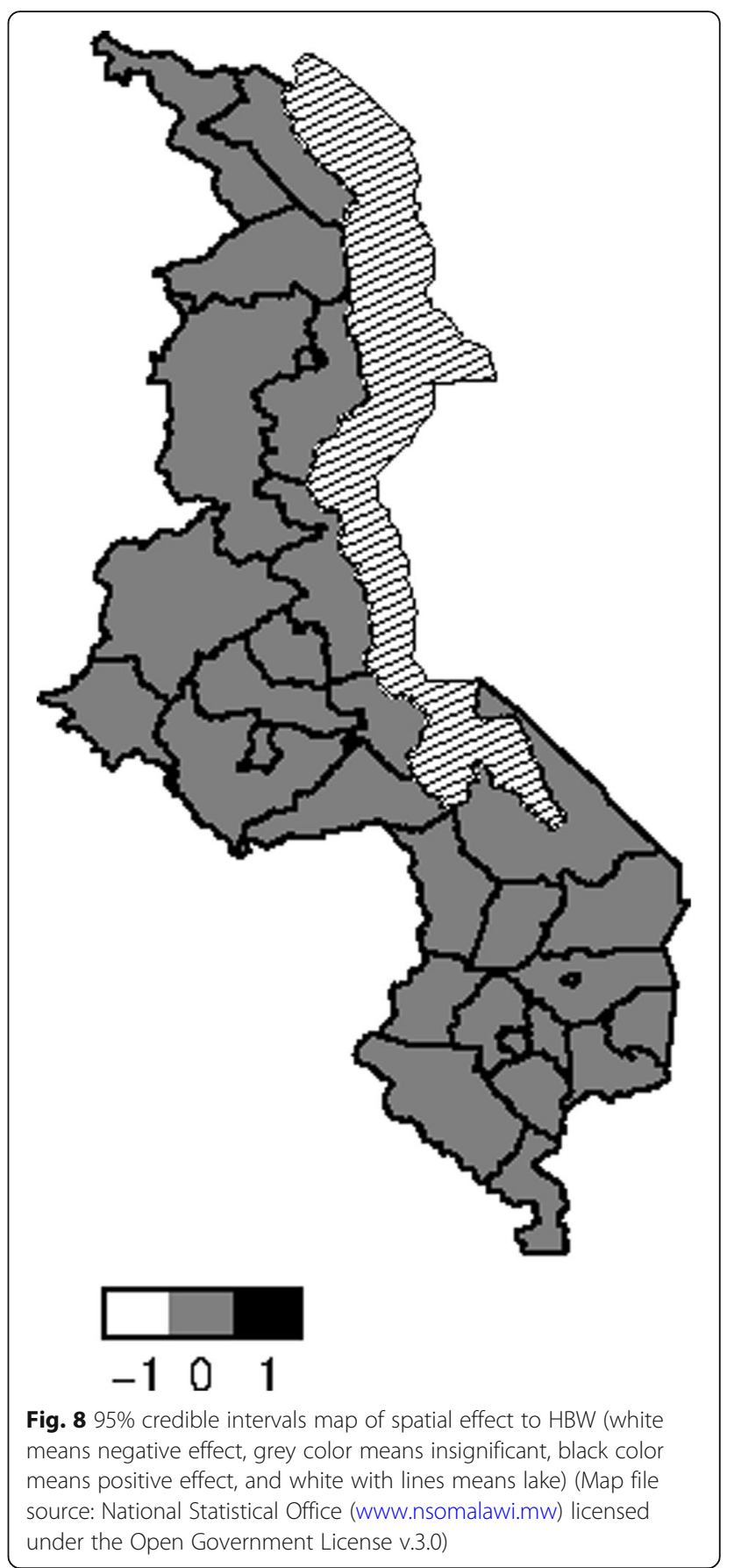

resources such as soil type and land slope, area population density, and distance to health facilities would be some of these factors. In this case, things like soil type and slope may have an impact on crop yield which may have an effect on mother nutrition. Number of people per unit area may affect spatial distribution in child birth weight in the way that, high number of people per unit area may induce competition for food in the area which may affect mother nutrition. Maternal nutrition in turn may directly affect child birth weight. Time taken to go 
to health facility affect mother number of times of going to the health facilities for prenatal care which can have an impact on baby birth weight. The spatial disparities observed between the south, and both centre and north could be from the fact that the southern region is relatively more developed than the north and centre in terms of hospitals, roads and schools among others and hence more likely to have improved maternal health indicators like nutrition which have an impact on child birth weight. For example according to MDHS 2010 report [12] on mother micro nutrient intake, women in the southern region have relatively more days of receiving iron tablet or syrup during their pregnancy than their counterparts in the northern and central region.

The study did not go without weaknesses. Since the study was cross sectional in design, no causal inference can be made between the outcome and the independent variables. In addition, since the study used secondary data, there was limitation in the inclusion of some variables, that is, variables not in the data but known to be associated with outcome. For instance, pregnancy history which is known to influence birth weight according to [38] could not be incorporated in the study.

\section{Conclusion}

The study supports non linear modeling of some covariates like mother age and antenatal visits that show nonlinear effect. Nonetheless there is no support of incorporating location as a spatial effect as there was no significant spatial variation of child birth weight. Nonetheless, the spatial patterns shown reveal the effect of unmeasured variables with some spatial dependence or may be epidemiological processes that are responsible for this spatial dependence, and the maps created can be used for prioritizing the areas with high risk. Strategies to minimize low/high birth weight must include education for mothers, weight gain during pregnancy in this study approximated by mother weight, and poverty reduction especially in areas shown to increase low/high birth weight.

\section{Supplementary information}

Supplementary information accompanies this paper at https://doi.org/10. 1186/s12889-019-7949-9.

Additional file 1. Child birth weight data.

\section{Abbreviations}

BMI: Body mass index; CDC: Centre for disease and control; DIC: Deviance information criterion; GMRF: Gaussian markov random field; HBW: High birth weight; ICAR: Intrinsic conditional autoregressive; INLA: Integrated nested laplace approximations; LBW: Low birth weight; MCMC: Markov chain monte carlo; MDHS: Malawi demographic health survey; NSO: National statistical office

\section{Acknowledgements}

I would like to thank the demographic healthy survey (DHS) for providing the data that was used in the study. I also thank the anonymous reviewers for the paper.

\section{Author's contributions}

AN conceived and analyzed the study, drafted and reviewed the manuscript.

\section{Funding}

This research did not receive any specific grant from funding agencies in the public, commercial, or not-for-profit sectors.

\section{Availability of data and materials}

All data generated or analyzed during this study are included in this published article [and it is additional file].

Ethics approval and consent to participate

Ethical approval was not applicable as the study used the secondary data collected by Malawi demographic health survey (MDHS) who granted permission to use the data.

\section{Consent for publication}

Not applicable.

\section{Competing interests}

The author declares that he has no competing interests.

Received: 25 February 2019 Accepted: 13 November 2019

Published online: 29 November 2019

\section{References}

1. Webb R. High birth weight and socio-economic status: University of Canterbury; 2011. Available from: www.nzae.org.nz/wp [Cited 21 Aug 2015]

2. Choukem S, Njim T, Atashili J, Shield J, Mbu R. High birth weight in a suburban hospital in Cameroon: an analysis of the clinical cut-off, prevalence, predictors and adverse outcomes. BMJOpen. 2016;6:e011517.

3. Ju H, Chadha Y, Donovan T, O'Rourke P. Fetal macrosomia and pregnancy outcomes. Aust N Z J Obstet Gynaecol. 2009;49:504-9.

4. Bérard J, Dufour P, Vinatier D, Subtil D, Vanderstichèle S, Monnier JC, Puech F. Fetal macrosomia: risk factors and outcome a study of the outcome concerning 100 cases >4500g. Eur J Obstet Gynecol Reprod Biol. 1998;77(1): $51-9$.

5. Sinclair BA, Rowan JA, Hainsworth OT. Macrosomic infants are not all equal. Aust N Z J Obstet Gynaecol. 2007;47:101-5.

6. Srofenyoh EK. Prenatal, labor and delivery characteristics of mothers with macrosomic babies. Int J Gynecol Obstet. 2006;93:49-50.

7. Boulet SL, Alexander GR, Salihu HM, Pass M. Macrosomic births in the United States: determinants, outcomes, and proposed grades of risk. Am J Obstet Gynecol. 2003;188(5):1372-8.

8. Mathew M, Machado L, Al-Ghabshi R, Al-Haddabi R. Fetal macrosomia: risk factors and outcome. Saudi Med J. 2005;26(1):96-100.

9. Cesur R, Kelly IR. From cradle to classroom: high birth weight and cognitive outcomes. Health Econ. 2010;13(2):9.

10. Seidman DS, Laor A, Gale R, Stevenson DK, Danon YL. A longitudinal study of birth weight and being overweight in late adolescence. Am J Dis Child. 1991;145(7):782-5

11. United Nations Children's Fund and World Health Organization. Low Birthweight: Country, regional and global estimates. New York: UNICEF; 2004.

12. NSO. Malawi DHS 2010-Final Report (English). 2011. Available from: http://www.measuredhs.com/publication [Cited 1 June 2013].

13. Robker RL. Effects of obesity on female fertility. Obes Res Clin Pract. 2011;5:3.

14. Sathyapalan T, Mellor D, Atkin SL. Obesity and gestational diabetes. Semin Fetal Neonat Med. 2010;15(2):89-93.

15. Shepard MJ, Bakketeig LS, Jacobsen G, O'Connor T, Bracken MB. Maternal body mass, proportional weight gain, and fetal growth in parous women. Paediatr Perinat Epidemiol. 1996;10(2):207-19.

16. Mumbare SS, Maindarkar G, Darade R, Yenge S, Tolani MK, Patole K. Maternal risk factors associated with term low birth weight neonates: a matched-pair case control study. Indian Pediatr. 2012;49:15-6 PMID: 22318099.

17. Muula AS, Siziya S, Rudatsikira E. Parity and maternal education are associated with low birth weight in Malawi. Afr Health Sci. 2011;11(1):65-71. 
18. Viengsakhone L, Yoshida Y, Rashid H, Sakamoto J. Factors affecting low birth weight at four central hospitals in Vientiane, Lao PDR. Nagoya J Med Sci. 2010;72:51-8.

19. Molraes AB, Zanini RR, Giugliani ERJ, Ribold J. Risk factors for low birth weight in Rio Grandedo Sul state, Brazil: classical and multilevel analysis. Cad. Saúde Pública, Rio de Janeiro. 2012;28(12):2293-305.

20. Nascimento LF. Hierarchical analysis of risk factors regarding low birth weight. Rev Paul Pediatr. 2005;23:76-82.

21. Nascimento LF, Moreira DA. Are environmental pollutants risk factors for low birth weight? Cad Saude Publica. 2009;25:1791-6.

22. Ngwira A, Stanley CC. Determinants of low birth weight in Malawi: Bayesian geo additive Modelling. PLoS One. 2015;10:6

23. Kamman EE, Wand MP. Geoadditive models.J Royal Stat Soc C. 2003:52:1-18.

24. Demelash H, Motbainor A, Nigatu D, Gashaw K, Melese A. Risk factors for low birth weight in bale zone hospitals, South-East Ethiopia : a case-control study. BMC Pregnancy Childbirth. 2015;15:264.

25. Wecker WE, Ansley CF. The signal extraction approach to nonlinear regression and spline smoothing. J Am Stat Assoc. 1983;78:81-9.

26. Besag J, Kooperberg C. On conditional and intrinsic autoregressions. Biometrika. 1995:82:733-46.

27. Fahrmeir L, Kneib T, Lang S. Penalized structured additive regression for space-time data: a Bayesian perspective. Stat Sin. 2004;14(3):731-61.

28. Yue $Y$, Rue $H$. Bayesian inference for structured additive quantile regression models. 2009. Available from: https://www.pdfs.semanticscholar.org/9685. [cited 15 Jan 2017]

29. Gelman A. Struggles with survey weighting and regression modeling. Stat Sci. 2007;22(2):153-64.

30. Kang J, Bernstein K. On Bayesian Inference with Complex Survey Data. Biom Biostat Int J. .2016;3(5):00076.

31. Gayawana E, Arogundade E, Adebayo S. Possible determinants and spatial patterns of anaemia among young children in Nigeria: a Bayesian semiparametric modeling. Int Health. 2014;6:35-45.

32. Kang SY, Cramb SM, White NM, Ball SJ, Mengersen KL. Making the most of spatial information in health: a tutorial in Bayesian disease mapping for areal data. Geospat Health. 2016;11(2):428.

33. Dubois L, Girard M, Tatone-Tokuda F. Determinants of high birth weight by geographic region in Canada. Chron Dis Can. 2007:28:1-2.

34. Magadi MA, Diamond I, Madise N. Individual and community-level factors associated with premature births, size of baby at birth and caesarean section deliveries in Kenya. African Population and Health Research Centre: Nairobi; 2000.

35. Wojcicki JM, Hessol NA, Heyman MB, Fuentes-Afflick E. Risk factors for macrosomia in infants born to Latina women. J Perinatol. 2008;28(11):743-9.

36. Abrevaya J, Dahl C. The effects of birth inputs on birthweight. J Bus Econ Stat. 2008;26(4):379-97

37. Francis MR, Rakesh PS, Mohan VR, Balraj V, George K. Examining spatial patterns in the distribution of low birth weight babies in southern Indiathe role of maternal, socio economic and environmental factors. Int J Biol Med Res. 2012;3(1):1255-9.

38. Badshah S, Mason L, Mckelvie K, Payne R, Lisboa PJ. Risk factors for low birth weight in the public hospitals at Peshawar, NWFP-Pakistan. BMC Public Health. 2008;8:197.

\section{Publisher's Note}

Springer Nature remains neutral with regard to jurisdictional claims in published maps and institutional affiliations.

Ready to submit your research? Choose BMC and benefit from:

- fast, convenient online submission

- thorough peer review by experienced researchers in your field

- rapid publication on acceptance

- support for research data, including large and complex data types

- gold Open Access which fosters wider collaboration and increased citations

- maximum visibility for your research: over $100 \mathrm{M}$ website views per year

At $\mathrm{BMC}$, research is always in progress.

Learn more biomedcentral.com/submissions 